\title{
A Comparative Study on Boride Layer Morphology of Fe-4Co, Fe-4V and Fe-4W Binary Alloys
}

\author{
Y. Azakli, K.O. Gunduz, M. Tarakci, Y. Gencer* \\ Gebze Institute of Technology, Department of Materials Science and Engineering, \\ Istanbul Cad. No 101, 41400 Gebze, Kocaeli, Turkey
}

\begin{abstract}
In this study, the pack boronizing behavior of Fe-4M alloys (at.\% $\mathrm{M}=\mathrm{W}, \mathrm{V}, \mathrm{Co}$ ) along with pure iron was investigated. The boronizing process was carried out at $1100{ }^{\circ} \mathrm{C}$ for $3 \mathrm{~h}$. The morphology, microstructure, boride layer thickness and surface properties of the formed boride layers were characterized by XRD, SEM-EDS and profilometry. The average boride layer thicknesses were $85 \mu \mathrm{m}, 130 \mu \mathrm{m}, 275 \mu \mathrm{m}$ and $280 \mu \mathrm{m}$ for Fe-4W, Fe-4V, Fe-4Co binary alloys and pure Fe, respectively. The surface roughness was not changed with the addition of alloying element into the substrate. $\mathrm{FeB}$ and $\mathrm{Fe}_{2} \mathrm{~B}$ phases exist on all boronized samples, but their ratio changes owing to alloying elements in the substrate. The saw-tooth morphology has transformed to a smoother boride layer with the addition of alloying elements of $\mathrm{W}$ and $\mathrm{V}$, though Co addition was ineffective on saw tooth morphology. In addition, a transition zone under the boride layer was observed for the boronized Fe- W and Fe- $\mathrm{V}$ alloys. The formation of precipitates of boride of alloying elements was evident in the boride layer and in the transition zone for borided $\mathrm{Fe}-4 \mathrm{~V}$ and $\mathrm{Fe}-4 \mathrm{~W}$ alloys. Co has made a solid solution with iron in boride by replacing iron in the boride lattice.
\end{abstract}

DOI: 10.12693 /APhysPolA.127.1326

PACS: 81.65.Lp, 81.05.Je, 81.05.Bx

\section{Introduction}

Borides are an important class of ceramic materials formed upon reaction between boron and other elements [1-4]. Generally, borides have high melting point, hardness, wear and corrosion resistance due to strong covalent bonding and high free formation energy. In addition, owing to their low electrical resistivity $(5-80 \mu \Omega)$ borides have excellent thermal shock resistivity $[5,6]$. Therefore they are excellent candidates as wear and corrosion resistant coatings, even at elevated temperatures $\left(\sim 600{ }^{\circ} \mathrm{C}\right)$ [4]. One way to form borides on ferrous and non-ferrous materials is boronizing. Boronizing is a thermochemical surface treatment method in which boron atoms diffuse into the substrate and form the desired boride compounds [7-9]. There are various parameters affecting the phase composition, microstructure and mechanical properties of the coatings, such as temperature, time, boronizing media and chemical composition of the substrate $[2,7]$. The chemical composition of the substrate can affect the boride layers in various ways. There can form a solid solution and enter the boride layer or there can also form precipitates in, or beneath, the boride layer, thus modifying their properties during the process [10-12]. Consequently it is important to determine the effect of alloying elements as a process parameter, especially in boronizing of steels. The effect of the chemical compositions of steels on boronizing behavior is rather complicated, owing to wide variety of alloying elements present in steels. Consequently, for boronizing of binary

\footnotetext{
*corresponding author; e-mail: gencer@gyte.edu.tr
}

$\mathrm{Fe}-\mathrm{M}(\mathrm{M}=\mathrm{Cr}, \mathrm{Ni}, \mathrm{Ti}, \mathrm{W}, \mathrm{Mn}, \mathrm{Si}, \mathrm{V}$ etc. $)$ alloys it is more desirable to understand the specific effect of each alloying element in steels $[1,7,10,11,13-15]$. There is a limited number of systematical studies, reported in the literature, to show the specific effect of some alloying elements on boronizing behavior of pure iron $[1,7,10$, $11,13-15]$.

The purpose of this study was to compare the effect of alloying of important tool steels with elements of $\mathrm{V}, \mathrm{W}$, $\mathrm{Co}$, on boronizing behavior of pure iron. Binary Fe-M $(\mathrm{M}=\mathrm{V}, \mathrm{W}, \mathrm{Co})$ alloys, containing the same amount of alloying elements of 4 at.\%, have been prepared by arc melting under vacuum/argon controlled atmosphere and boronized by pack boronizing method. The study was focused on comparison of thickness, surface roughness, morphology, phase composition and microstructure of the boride layers formed on Fe-M alloys as well as on pure iron. The borided samples were characterized by using XRD, SEM, EDS, OM and profilometry.

\section{Experimental}

W, V, Co and Fe with the purity of $99.95 \%$ were melted under argon atmosphere by using a vacuum/atmosphere controlled arc melter in order to produce binary Fe-M $(\mathrm{M}=\mathrm{W}, \mathrm{V}, \mathrm{Co})$ alloys containing 4 at.\% of each element. Hereafter, the sample substrates will be named as Fe- $4 \mathrm{~W}$, Fe- $4 \mathrm{~V}, \mathrm{Fe}-4 \mathrm{Co}$, accordingly. After producing the alloys, each of them was sliced into the samples with the dimensions of $10 \times 10 \times 5 \mathrm{~mm}^{3}$. Before boronizing process, samples were ground using 240-1200 grit emery paper and then polished using $3 \mu \mathrm{m}$ diamond solution. A pure iron sample with the same dimensions was prepared similarly for comparison. Ekabor II powder was chosen as 
boron source with the approximate chemical composition of $90 \% \mathrm{SiC}, 5 \% \mathrm{~B}_{4} \mathrm{C}$ and $5 \% \mathrm{KBF}_{4}$. The boronizing process was carried out at $1100{ }^{\circ} \mathrm{C}$ in an electrical box furnace for 3 hours under atmospheric conditions. The temperature deviation during the treatment was $\pm 5^{\circ} \mathrm{C}$. The samples were cooled to room temperature in air. After boronizing process, the samples were ultrasonically cleaned in acetone and then warm-air dried. The surface roughness measurements of the samples were conducted using Veeco Dektak 8 profilometer. An area of $4 \mathrm{~mm}^{2}$ on the center of borided samples was scanned in mapping mode with a total of 20 scans. X-ray phase characterization of the borided samples was carried out by Bruker $\mathrm{D} 8 \mathrm{X}$-ray diffractometer with a $\mathrm{CuK}_{\alpha}$ radiation, over a $2 \theta$ range from $20^{\circ}$ to $90^{\circ}$ with a scan rate of $2^{\circ} / \mathrm{min}$. The borided samples were cut through the diameter into two pieces using a precision diamond saw to expose the cross section of the coating. One-half of each sample was mounted in resin, in order to perform microstructural and elemental analysis. Right after, samples in resin were ground using 80-1200 grit emery paper and polished using $3 \mu \mathrm{m}$ diamond paste. Philips XL 30 Scanning Electron Microscope (SEM) with an energy dispersive spectrometer (EDS) detector was employed for the cross sectional microstructure examination and elemental analysis.

\section{Results}

Figures 1a, 1b, 1c and 1d illustrate the cross sectional SEM micrographs of borided pure iron, Fe-4Co, Fe-4W and Fe- $4 \mathrm{~V}$ binary alloys, respectively. There are two parts of the cross sectional SEM micrographs for binary $\mathrm{Fe}-4 \mathrm{~V}$ and $\mathrm{Fe}-4 \mathrm{~W}$ alloys, one with low magnification and a section of it with a higher magnification, to show the general and detailed nature of the boride layers, while the SEM micrographs of borided pure Fe and Fe-4Co alloy consist of a single micrograph. Cross sectional SEM examinations revealed that there were two distinct zones in borided pure iron and $\mathrm{Fe}-4 \mathrm{Co}$; (i) boride layer, (ii) substrate material, whereas three distinct zones were observed in borided Fe-4V and Fe-4W; (i) boride layer, (ii) transition zone composed of precipitates, (iii) substrate material. The saw tooth morphology has been observed in borided pure iron, Fe-4Co and $\mathrm{Fe}-4 \mathrm{~W}$. However the penetration depth and size of the boride teeth in borided Fe-4W was smaller compared to borided pure iron and Fe-4Co alloy. Furthermore the interface between boride layer and transition zone in borided $\mathrm{Fe}-4 \mathrm{~W}$ alloy was not distinct. The interface between boride layer and transition zone of borided Fe- $4 \mathrm{~V}$ is relatively smooth and flattened out, compared to the other borided samples.

In addition, the boride layer on borided Fe- $4 \mathrm{~V}$ alloy showed a contrast, with an outer dark region and a lighter inner region and a crack was evident between these regions. There is also a contrast between the outer and inner regions of the borided Fe- $4 \mathrm{~W}$ alloys, even though not as distinct as in the borided Fe- $4 \mathrm{~V}$ alloy. The darker regions are corresponding to the boron rich FeB phase,
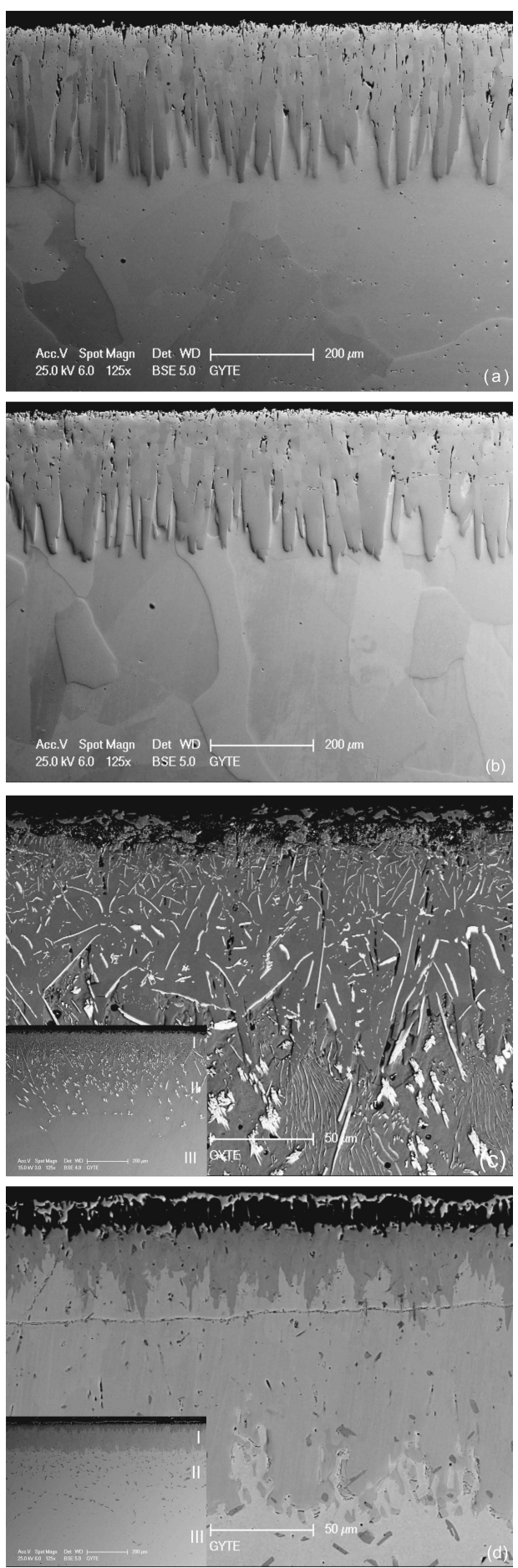

Fig. 1. Cross-sectional SEM micrographs of borided samples; a) pure iron, b) Fe-4Co, c) Fe-4W and d) $\mathrm{Fe}-4 \mathrm{~V}$.

while the brighter regions are corresponding to $\mathrm{Fe}_{2} \mathrm{~B}$ phase, as reported in the literature for borided ferrous alloys $[7,10,11]$. No cracks have been observed in samples other than borided Fe- $4 \mathrm{~V}$ alloy. The outer skin of boride layers was porous and might be flaked off during the preparation. 
The pore concentration in boride layers is highest in borided pure iron. Cobalt addition has a little effect on pore concentration. On the other hand, vanadium and tungsten greatly reduced the pore concentration and hence a dense boride layer was formed. Precipitates were evident for borided Fe- $4 \mathrm{~V}$ and $\mathrm{Fe}-4 \mathrm{~W}$ alloys both in and beneath the boride layer, though the quantity of precipitates in borided $\mathrm{Fe}-4 \mathrm{~W}$ was much higher, compared to borided Fe- $4 \mathrm{~V}$ alloy. However the concentration of precipitates is higher in the transition zone for both alloys. The precipitates were irregular in shape in borided Fe- $4 \mathrm{~V}$ alloy, while the shape of the precipitates was mostly acicular in borided Fe-4W alloy. The precipitates in the transition zone were coarser than those in the boride layer, particularly in the outer region of the coating in borided $\mathrm{Fe}-4 \mathrm{~W}$ and $\mathrm{Fe}-\mathrm{V}$ alloys.

The surface XRD results of borided $\mathrm{Fe}-4 \mathrm{~W}, \mathrm{Fe}-4 \mathrm{Co}$, Fe-4V and pure iron are given in Fig. 2. The XRD patterns show that the boride layers are composed of FeB and $\mathrm{Fe}_{2} \mathrm{~B}$ phases for all borided samples, except for borided $\mathrm{Fe}-4 \mathrm{~V}$, on which only $\mathrm{FeB}$ phase was detected. However, the presence of $\mathrm{FeB}$ phase in borided pure iron is not very significant, compared to other borided samples. It should be noted that the presence of the precipitates which were seen on the cross sectional micrograph of the coatings was not confirmed by XRD for the borided $\mathrm{Fe}-4 \mathrm{~W}$ and $\mathrm{Fe}-4 \mathrm{~V}$ alloys.

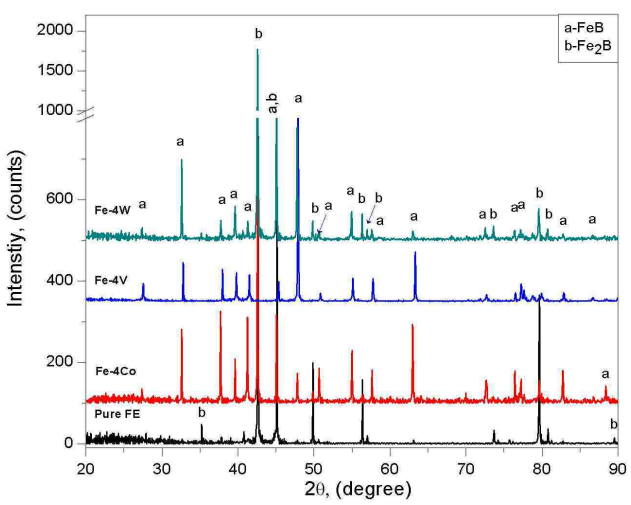

Fig. 2. Surface XRD pattern of borided Fe-4M alloys and pure Fe.

Figures $3 \mathrm{a}$ and $3 \mathrm{~b}$ show the thickness and roughness values of boride layers formed on the surface of $\mathrm{Fe}-4 \mathrm{~W}$, $\mathrm{Fe}-4 \mathrm{Co}$ and $\mathrm{Fe}-4 \mathrm{~V}$ alloys and pure iron. The thickest boride layer of all samples was measured on pure iron as approximately $280 \mu \mathrm{m}$ and the thinnest boride layer was measured on borided Fe- $4 \mathrm{~W}$ alloy as approximately $85 \mu \mathrm{m}$. The presence of 4 at.\% of Co in the iron substrate has not considerably changed the boride layer thickness, compared to the pure iron boride layer and it was approximately $275 \mu \mathrm{m}$. Figure $3 \mathrm{~b}$ shows also the surface roughness of the borided Fe-4M alloys. The lowest and the highest roughness values were measured on borided Fe-4W and Fe-4Co as $1.25 \mu \mathrm{m}$ and $1.85 \mu \mathrm{m}$, respectively. The surface roughness of the borided samples did not change considerably depending on the alloying elements in the substrates.

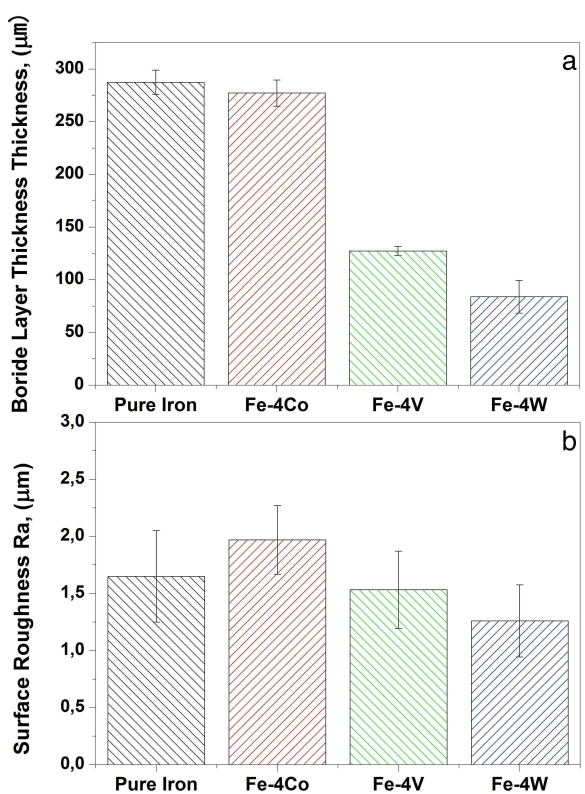

Fig. 3. The comparison of the effect of alloying element on; (a) boride layer thickness and (b) surface roughness (Ra).

The elemental distribution obtained from the borided $\mathrm{Fe}-4 \mathrm{Co}, \mathrm{Fe}-4 \mathrm{~W}$ and $\mathrm{Fe}-4 \mathrm{~V}$ alloys are shown in the SEMEDS spectrum (Fig. 4a-4c) along a line from the surface of boride layer to the substrate with cross-sectional SEM images. The spectrum of Fe-4Co alloy (Fig. 4a) shows that the concentration of $\mathrm{Fe}$ and $\mathrm{Co}$ was almost constant from the substrate towards the boride layer with some scattering. When the SEM/EDS line reached to boride layer, Fe and Co concentration decreased and boron concentration ascended. Figure $4 \mathrm{~b}$ shows the concentration profile of the elements in Fe- $4 \mathrm{~W}$. The concentration profile of $\mathrm{Fe}$ and $\mathrm{W}$ elements follow a constant line with some scatter along the coating on the substrate of Fe- $4 \mathrm{~W}$ alloy. The concentration of $\mathrm{W}$ and $\mathrm{B}$ elements decrease while the EDS line passes through the precipitates on the transition zone and boride layer. The change in $\mathrm{B}$ and $\mathrm{Fe}$ concentration profile was similar for the borided Fe- $4 \mathrm{~V}$ and Fe-4W alloys (Fig. 4b-4c). That is to say, Fe concentration decreases and $\mathrm{B}$ concentration increases on the precipitates present over the transition zone and boride layer. Also the $\mathrm{V}$ profile shows peaks over precipitates and slightly decreases through the boride layer.

\section{Discussion}

Present experimental studies revealed that alloying elements of Co, $\mathrm{V}$ and $\mathrm{W}$ have considerable effect on morphology, thickness, formed phases and chemical composition of the boride layer.

Addition of $\mathrm{Co}$ to pure iron slightly decreased the thickness, densified the boride layer and coarsened the boride crystals with similar tooth morphology, though it has no effect on the phases forming during the boronizing process. The line SEM-EDS studies of the borided 

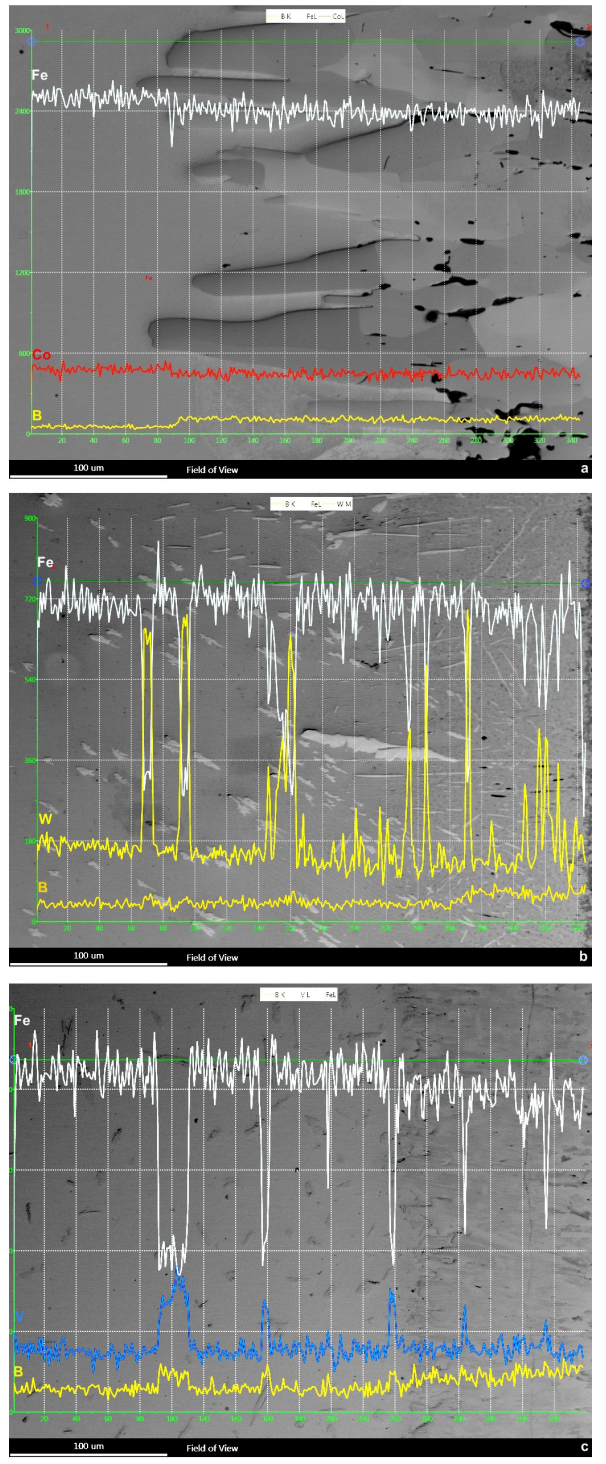

Fig. 4. Line-SEM/EDS spectra of the borided binary alloys with the cross-sectional SEM micrographs; (a) $\mathrm{Fe}-4 \mathrm{Co},(\mathrm{b}) \mathrm{Fe}-4 \mathrm{~W}$ and (c) Fe-4V.

Fe-4Co revealed a uniform distribution of cobalt in the boride layer and in the substrate. These results can be attributed to the similarities of chemical activity, atomic radius of iron and cobalt. Also the uniform distribution of cobalt supports that Co has made a solid solution with iron in boride by replacing iron in the boride lattice. A study made by Liu also shows that Co can be dissolved in $\mathrm{FeB}$ and $\mathrm{FeB}_{2}$ in all compositions [16]. The decrease in coating thickness and coarsening of boride crystals in the boride layer can be attributed to a slight hindrance of boron atoms due to presence of cobalt atoms in iron substrate. Presence of this phenomenon is also supported by XRD analysis which shows that, the intensity of the peaks belonging to FeB phase detected in borided Fe-4Co is much higher compared to borided pure iron. However, this FeB layer is not observed by cross sectional SEM examination of the borided Fe-4Co alloy. It may be either because of the flake-off of $\mathrm{FeB}$ during the preparation of samples for the cross sectional examinations, or FeB phase was formed on the surface locally which did not allow us to visualize the FeB by cross sectional examination.

The vanadium addition has decreased the thickness of the boride layer significantly, flattened the boride crystals and increased the thickness of FeB layer. Irregularly shaped precipitates were evident both in and beneath the boride layer, while they were much higher in quantity in the transition zone, compared to the amount of precipitates in boride layer of Fe-4V. Moreover, the precipitates in the transition zone were coarser, compared to the precipitates in the boride layer. The line SEMEDS results also revealed that these precipitates were rich in vanadium and boron and they were also containing a small amount of iron. Additionally, the porosity level of the boride layer is lower, compared to borided pure iron. The effect on the morphology and on the decrease of boride layer thickness can be attributed to the formation of a diffusion barrier due to the presence of the precipitates both in and beneath the boride layer. These precipitates retarded the boron diffusion into the substrate resulting in a decrease of the coating thickness and flattening of the saw tooth morphology. A detailed study made by Gencer et al. revealed that these precipitates were $\mathrm{V}_{5} \mathrm{~B}_{6}$ in nature, containing a little amount of iron [11]. It was also stated that these precipitates were formed during the early stages of the boronizing process, due to the high reactivity between vanadium and boron. The diffusion barrier effect of $\mathrm{V}$ also was seen on XRD pattern, where only the presence of $\mathrm{FeB}$ was detected, though $\mathrm{Fe}_{2} \mathrm{~B}$ phase's existence was evident in the cross sectional SEM image. A crack was observed at the interface between the $\mathrm{FeB}$ and $\mathrm{Fe}_{2} \mathrm{~B}$ layer of borided $\mathrm{Fe}-4 \mathrm{~V}$ alloy. This crack is formed due to differences in thermal expansion coefficients of $\mathrm{FeB}\left(2.3 \times 10^{-5}{ }^{\circ} \mathrm{C}^{-1}\right)$ and $\mathrm{Fe}_{2} \mathrm{~B}$ $\left(7.85 \times 10^{-6}{ }^{\circ} \mathrm{C}^{-1}\right)[7]$.

Addition of tungsten into pure iron has decreased the thickness and porosity level and has intensified the peaks of $\mathrm{FeB}$ phase. However, $\mathrm{FeB}$ and $\mathrm{Fe}_{2} \mathrm{~B}$ phases could not be distinctly seen, as it was observed in SEM image of $\mathrm{Fe}-4 \mathrm{~V}$. Tungsten content also resulted in a shallower tooth saw structure and the flattened boride layersubstrate interface. This can be attributed to physical obscuring of iron boride layer by the tungsten-rich precipitates, which formed in the early stages of boriding process. Also, tungsten atoms in solid solution, formed in the iron boride layer, have hindered the boron diffusion by decreasing the diffusion coefficient. According to the line SEM-EDS results, precipitates observed in microstructure were rich in tungsten and boron. The formation of these precipitates can be attributed to high reactivity [10] between tungsten and boron. A study made by Azakli showed that the precipitates in the boride layer were of tungsten and boron rich $\mathrm{FeW}_{2} \mathrm{~B}_{2}$ phase, while precipitates in the transition zone were corresponding to 
the FeWB phase, which was containing less boron and iron [14]. There is no systematic change in the surface roughness values of the borided samples and these values are independent of the alloying element addition.

\section{Conclusions}

In this study binary $\mathrm{Fe}-\mathrm{M}(\mathrm{M}=\mathrm{Co}, \mathrm{V}, \mathrm{W})$ alloys have been borided and each alloying element affected the properties of the obtained boride layer properties significantly. The following results can be derived:

1. The thickest boride layer was obtained on borided pure iron $(280 \mu \mathrm{m})$ while the thinnest coating was obtained on borided Fe- $4 \mathrm{~W}$ alloy $(85 \mu \mathrm{m})$.

2. Two distinct zones were observed for borided pure iron and Fe-4Co alloy, namely (i) boride layer and (ii) substrate, whereas three distinct zones were observed for borided Fe- $4 \mathrm{~V}$ and Fe- $4 \mathrm{~W}$ alloys, namely (i) boride layer, (ii) transition zone composed of precipitates and (iii) substrate.

3. The tooth saw morphology has been observed on borided pure iron. Cobalt addition didn't have a significant effect on the saw tooth morphology, it only coarsened the boride teeth in a minor degree. Tungsten addition greatly reduced the longitudinal size of the boride teeth, made the interface much more smoother compared to pure iron and $\mathrm{Fe}-4 \mathrm{Co}$. Vanadium addition has the utmost effect on the saw tooth morphology, it completely smoothened the interface and formed a relatively flat interface.

4. Co addition has no effect on the phase composition and cobalt atoms have been distributed both in the boride layer and substrate homogeneously, while vanadium and tungsten addition formed precipitates both in and beneath the boride layer. In addition a distinct FeB phase was evident in borided Fe- $4 \mathrm{~V}$ alloy, which can be clearly identified from the cross-sectional SEM examinations. FeB phase is also present in the borided Fe-4W alloys, however it was discontinuous and relatively thinner than in the borided Fe-4V alloys.

5. Vanadium and boron rich precipitates containing a little amount of iron were evident in the borided Fe- $4 \mathrm{~V}$ alloy, while tungsten and boron rich precipitates containing also a little amount of iron were present in the borided Fe- $4 \mathrm{~W}$ alloy. The precipitates were coarser in the transition zone than the precipitates in the boride layers of both alloys.

\section{References}

[1] M. Tarakci, Y. Gencer, Y. Azakli, U. Sahinturk, Journal of The Faculty of Engineering and Architecture of Gazi University 28, 645 (2013).

[2] O. Ozdemir, M. Usta, C. Bindal, A.H. Ucisik, Vacuum 80, 1391 (2006).

[3] O. Ozdemir, M.A. Omar, M. Usta, S. Zeytin, C. Bindal, A.H. Ucisik, Vacuum 83, 175 (2008).

[4] A.K. Sinha, Boriding (boronizing) in: ASM Handbook, pp. 437-447, 1991.

[5] C. Raymonf, A. Cutler, Engineering Properties of Borides in: Ceramics and Glasses, ASM International, United States of America, pp. 787-803, 1991.

[6] S. Sen, I. Ozbek, U. Sen, C. Bindal, Surf. Coat. Tech. 135, 173 (2001).

[7] Y. Gencer, Surf. Eng. 27, 634 (2011).

[8] D. Mu, C. Yang, B.L. Shen, H. Jiang, J. Alloys Compd. 479, 629 (2009).

[9] M. Usta, Surf. Coat. Tech. 194, 251 (2005).

[10] Y. Gencer, M. Tarakci, A. Calik, Surf. Coat. Tech. 203, 9 (2008).

[11] K.O. Gunduz, Y. Gencer, M. Tarakci, A. Calik, Surf. Coat. Tech. 221, 104 (2013).

[12] V. Sista, O. Kahvecioglu, O.L. Eryilmaz, A. Erdemir, S. Timur, Thin Solid Films 520, 1582 (2011).

[13] C.M. Brakman, A.W.J. Gommers, E.J. Mittemeijer, J. Mater. Res. 4, 1354 (1989).

[14] Y. Azakli, Master's Thesis: Influence of Tungsten as Alloying Element on Boronizing Behaviour of Pure Iron, Material Science and Engineering, Gebze Institute of Technology, Gebze, 2012.

[15] Y.G.A. Calik, M. Tarakci, K.O. Gunduz, A.E. Gulec, Acta Physica Polonica A 123, 449 (2013).

[16] Y.Q. Liu, X.S. Zhao, J. Yang, J.Y. Shen, J. Alloys. Compd. 509, 4805 (2011). 